\title{
Preparação de membranas de PHB por eletrofiação e caracterização para aplicações em engenharia tecidual
}

\author{
Preparation of PHB membranes by \\ electrospinning and characterization \\ for tissue engineering applications
}

\author{
Sérgio Henrique Pezzin ${ }^{1}$, Águeda Sonseca Olalla ${ }^{2}$, \\ Enrique Giménez Torres ${ }^{2}$, André Luiz dos Santos ${ }^{3}$, \\ Marcia Adriana Tomaz Duarte ${ }^{3}$, Leandro da Silva ${ }^{4}$, \\ Juliana Almeida Domingues ${ }^{5}$
}

\footnotetext{
${ }^{1}$ Centro de Ciências Tecnológicas, Universidade do Estado de Santa Catarina, Joinville, Santa Catarina, Brasil.

${ }^{2}$ Instituto de Tecnologia de Materiais, Universidade Politécnica de Valência, Valência, Valência, Espanha.

${ }^{3}$ Mestrado Profissional em Engenharia Mecânica, Centro Universitário Tupy, Joinville, Santa Catarina, Brasil.

${ }^{4}$ Graduação em Engenharia Elétrica, Centro Universitário Tupy, Joinville, Santa Catarina, Brasil.

${ }^{5}$ Departamento de Biologia Celular e Estrutural, Universidade Estadual de Campinas, Campinas, São Paulo, Brasil. e-mail: sergio.pezzin@udesc.br, agsonol@posgrado.upv.es, enrique.gimenez@mcm.upv.es,

almeidajad_bio@hotmail.com, santandre@outlook.com, marcia.duarte@ sociesc.org.br, dasilvaleandro21@gmail.com
}

\section{RESUMO'}

Este trabalho tem como objetivo a preparação de mantas compostas por fibras do polímero biodegradável poli(3-hidroxibutirato) - (PHB) por meio da técnica de eletrofiação. Obtiveram-se mantas sob diferentes condições, variando-se o fluxo, a temperatura da solução, a tensão aplicada e a adição de um agente surfactante. $\mathrm{O}$ material obtido foi analisado por microscopia eletrônica de varredura (MEV), calorimetria exploratória diferencial (DSC), termogravimetria (TG), difratometria de raios-X (DRX) e viabilidade celular. A caracterização por MEV mostrou que os melhores resultados, apresentando as fibras com diâmetros constantes de $0,77 \mu \mathrm{m}$ e sem a formação de grãos, foram atingidos nas seguintes condições: concentração da solução de $10 \%$ (m/v) em CF/DMF (9/1), fluxo da solução de 5,8 ml/h, tensão de $17 \mathrm{kV}$ e adição de surfactante (dodecil-sulfato de sódio, SDS). Os resultados mostraram que as variações de vazão, tensão e a adição de surfactante não influenciam muito o diâmetro médio das fibras, enquanto o aumento da temperatura diminui este parâmetro. No entanto, a adição de um agente surfactante deixa a manta mais densa e com poros interconectados, além de permitir a proliferação celular, sendo então indicada para produção de mantas para uso como arcabouço.

Palavras-chave: Eletrofiação, poli (3-hidroxibutirato), PHB, Engenharia Tecidual.

\begin{abstract}
This work aims the preparing of mats composed of poly (3-hydroxybutyrate) - (PHB) biodegradable polymeric fibers, using the electrospinning technique. Mats were obtained under different conditions: changing the flow and temperature of the solution, tension and the addition of a surfactant to the solution. The obtained material was analyzed by scanning electron microscopy (SEM), differential scanning calorimetry (DSC), thermogravimetry (TG), X ray diffractometry (XRD) and cell viability. The characterization by SEM showed that the best results, presenting fibers with constant diameters of $0.77 \mu \mathrm{m}$ and without beads formation, were reached under the following conditions: concentration of $10 \%(\mathrm{~m} / \mathrm{v})$ solution in CF / DMF (9/1), solution flow of $5.8 \mathrm{ml} / \mathrm{h}, 17 \mathrm{kV}$ and addition of surfactant (sodium dodecylsulfate, SDS). The results showed that the variation of the flow, tension and surfactant did not influence the average diameter of the fibers, but the increase of the temperature decreases this parameter. Moreover, the addition of a surfactant increases the density of the blankets and interconnect the pores, allowing cellular proliferation, and, thus. it is indicated for use as scaffolds.
\end{abstract}


Keywords: Electrospinning, poly (3-hydroxybutyrate), PHB, Tissue Engineering.

\section{INTRODUÇÃO}

A eletrofiação é uma técnica usada para criar fibras com diâmetros numa vasta gama de nano a micrometros, a partir de soluções poliméricas [1,2]. Estas membranas compostas por fibras têm tamanhos de poros (interstícios entre as fibras) que são pequenos o suficiente para impedir a penetração de bactérias, por exemplo, além de área de superfície elevada de $5-100 \mathrm{~m}^{2} / \mathrm{g}$ o que é extremamente eficiente para a absorção de fluidos [3].

Estas fibras são obtidas pelo emprego de uma tensão da ordem de $\mathrm{kV}$, de corrente contínua $(\mathrm{CC})$ ou corrente alternada (CA), por uma fonte de alta tensão. Esta carga se acumula em uma gota, na extremidade de uma agulha de seringa que está sendo simultaneamente movimentada por uma bomba. Para isso é necessário um eletrodo em contato com a solução e outro em uma superfície coletora, ambos de material condutor de eletricidade. Um forte campo elétrico é gerado na distância entre a agulha e o coletor e, quando a força elétrica em contato com a superfície do líquido atinge um valor crítico, a gota muda de formato e é ejetada na forma de um jato de fluido, adquirindo velocidade e reduzindo a espessura ao passo em que o solvente é evaporado, até a fibra solidificada ser projetada no coletor $[4,1,5,6]$.

Algumas aplicações das nanofibras poliméricas, podem ser atribuídas a filtração, sensores, biomedicina, nanobiotecnologia, tecidos, curativos para feridas, liberação de fármacos e imobilização de enzimas, nanocompósitos, indústria de vestuário, compósitos estruturais, exocompósitos, sistemas de purificação de ar, bioengenharia, engenharia ambiental e eletrônica, indústrias energética, de defesa e segurança $[7,8,9,10]$.

De todos estes exemplos o campo biomédico e a engenharia de tecidos podem ser considerados os mais beneficiados pela técnica de eletrofiação. As interessantes propriedades como a específica alta área de superfície, alta porosidade e capacidade de absorção, encontram aplicação como curativos para feridas, que proporcionam uma boa drenagem e uma boa permeabilidade de ar, podem ser carregados com medicamentos e proporcionam conforto na aplicação e remoção do curativo. Também são aplicadas como um meio adequado para a regeneração do tecido devido às semelhanças estruturais físicas com a matriz extracelular dos tecidos, que funciona como uma estrutura que dá o suporte para o desenvolvimento, crescimento e conexão das células de diferentes partes do corpo fornecendo uma estrutura de biomateriais. Um exemplo, das possíveis injúrias que um ser humano pode apresentar, são as queimaduras, já que de um milhão de acidentes que ocorrem por ano, cerca de $2,5 \%$ vão a óbito $[11,12,13,14]$.

Os tipos de rugosidade destas fibras determinam o número e tipos de ancoragens das células com seu substrato e considerando a aplicação das mantas, ou seja, o tipo de tecido a ser desenvolvido (tecido vascular, neural, tendões, ligamentos ou ossos), a manipulação dos parâmetros para obtenção de morfologias específicas incluem considerar o material, orientação das fibras (alinhadas ou aleatórias), porosidade das fibras (relacionada a infiltração celular), para isso, os parâmetros que têm influência no processo devem ser controlados, podem-se citar: a tensão elétrica, corrente elétrica, vazão, temperatura e concentração da solução, a distância entre a extremidade da agulha e o tipo de coletor utilizado $[6,9,15,16,17,18]$.

Quanto aos materiais, os polímeros biodegradáveis apresentam várias possibilidades de aplicações na área biomédica, devido às suas biocompatibilidades e biodegradabilidades [19]. O tempo médio de degradação desses materiais é de 6 a 12 meses contra 40 a 50 anos ou até 200 anos no caso dos polímeros sintéticos [20].

O poli(3-hidroxibutirato), PHB, possui como características a biocompatibilidade [22] e a biodegradabilidade [20], podendo ser obtido de fontes renováveis. Deste modo, essas três principais características justificam seu estudo, para aplicação em engenharia tecidual, além de impulsionar o desenvolvimento, produção e aplicação de polímeros biodegradáveis, que minimizam os problemas gerados pelo descarte de plásticos de origem petroquímica lançados ao meio ambiente [23]. Ademais, o PHB é totalmente isotático e possui grau de cristalinidade na faixa de 55-80\%. A temperatura de transição vítrea ( $\mathrm{Tg}$ ) do PHB é de aproximadamente $5{ }^{\circ} \mathrm{C}$ e a temperatura de fusão $(\mathrm{Tm})$, de $175{ }^{\circ} \mathrm{C}$, acima de $170{ }^{\circ} \mathrm{C}$ ocorre diminuição na massa molecular [21].

Desta forma este trabalho tem como objetivo preparar e caracterizar mantas de PHB através da eletrofiação, verificando sua viabilidade celular para aplicação no desenvolvimento de um tecido epitelial orgânico visando futura aplicação como enxerto e recuperação de feridas epiteliais.

\section{MATERIAIS E MÉTODOS}

\subsection{Equipamento para eletrofiação}

O equipamento utilizado é composto por uma seringa para impulsionar a solução até uma agulha de aço ino- 
xidável, utiliza-se uma bomba de infusão para movimentar o êmbolo da seringa, e um coletor rotativo para deposição das fibras eletrofiadas composto por um tubo de cobre sem costura recheado com cimento leve. $\mathrm{O}$ coletor foi ligado a um motor de $135 \mathrm{~W}(24 \mathrm{~V})$ com controle de giros até $3400 \mathrm{rpm}$. Uma plataforma composta por uma chapa de fórmica foi usada para sustentar os componentes e um tubo de polietileno, com 1,59 mm de diâmetro foi utilizado para a transmissão da solução da seringa para a agulha. Além disso, foi utilizado um invólucro de acrílico para proteção do sistema, observado na Figura 1.

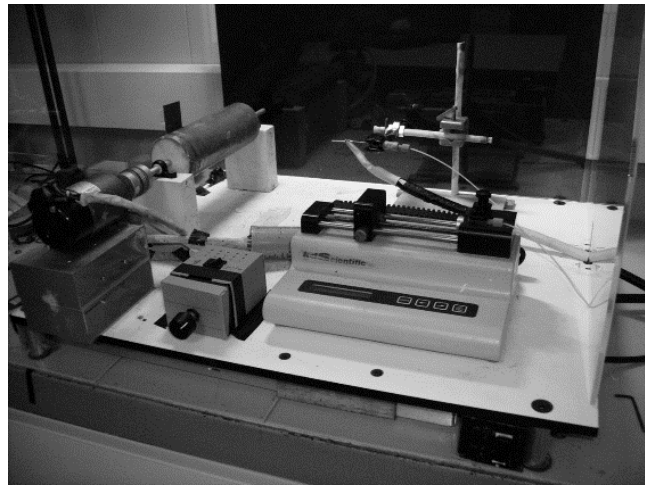

Figura 1: Equipamento utilizado para os experimentos de eletrofiação.

\subsection{Preparação das soluções}

O PHB utilizado nesta pesquisa foi gentilmente cedido pela PHB Industrial S.A. e apresenta massa molar numérica média de $3.0 \times 10^{5} \mathrm{~g} \mathrm{~mol}^{-1}$, obtida por cromatografia de permeação em gel (GPC). Os solventes (Fluka) foram utilizados sem tratamento prévio. A preparação das soluções se deu pela dissolução do PHB em clorofórmio (CF) e mesclas clorofórmio/dimetilformamida (CF/DMF), 9/1, em concentrações que variaram entre 3 e $14 \%$ m/v para experimentos de eletrofiação.

\subsection{Testes preliminares}

Foram realizados testes preliminares no equipamento para a obtenção das mantas, estudando os parâmetros ideais para o processo. Arbitrariamente os primeiros valores utilizados foram $20 \mathrm{~cm}$ de distância entre coletor e capilar e uma rotação de $1000 \mathrm{rpm}$. Após variações, chegou-se a uma distância adequada de $12 \mathrm{~cm}$, enquanto a velocidade de coletor foi mantida em $1000 \mathrm{rpm}$, devido ao fato de que em distâncias menores é a maior formação de grãos, enquanto em distâncias maiores as fibras tendiam a ficar descontínuas.

\subsection{Produção das membranas de PHB por eletrofiação}

Inicialmente, o primeiro parâmetro estudado foi a concentração da solução, de modo a testar três concentrações diferentes, $3 \%, 5 \%$ e $7 \%(\mathrm{~m} / \mathrm{v})$, utilizando-se os valores de $13 \mathrm{kV}$ para a tensão (Corrente contínua-CC), vazão da solução de $1,7 \mathrm{~mL} / \mathrm{h}$ (seringa pequena), distância do coletor $15 \mathrm{~cm}$, soluções em clorofórmio $(C F)$ e rotação do coletor de $1000 \mathrm{rpm}$. No entanto através de uma análise por MEV, estes ensaios foram desconsiderados, pois além da formação de grãos obtiveram-se poucas fibras, não formando uma manta contínua.

Nos demais ensaios foram estudados outros quatro parâmetros, conforme Tabela 1. Nestes ensaios mantiveram-se os parâmetros: distância do coletor $12 \mathrm{~cm}$, concentração das soluções de $10 \%$ (m/v) em clorofórmio/DMF (9/1) e rotação do coletor de $1000 \mathrm{rpm}$. 
Tabela 1: Tabela de controle dos parâmetros dos ensaios.

\begin{tabular}{l|l|l|l|l|l}
\hline Variável & Ensaio & Tensão $(\mathrm{kV})$ & Vazão $(\mathrm{ml} / \mathrm{h})$ & Surfactante $(\%$ SDS $)$ & Temperatura $\left({ }^{\circ} \mathrm{C}\right)$ \\
\hline \multirow{3}{*}{ Vazão } & $\mathrm{A}$ & 17 & 1,5 & - & 20 \\
\cline { 2 - 6 } & $\mathrm{B}$ & 17 & 3 & - & 20 \\
\cline { 2 - 6 } & $\mathrm{C}$ & 17 & 4,5 & - & 20 \\
\hline Tensão & $\mathrm{D}$ & 15 & 3 & - & 20 \\
\hline Surfactante & $\mathrm{E}$ & 17 & 3 & 0,5 & 20 \\
\hline Temperatura & $\mathrm{F}$ & 17 & 3 & - & 50 \\
\hline
\end{tabular}

\subsection{Microscopia Eletrônica de Varredura (MEV)}

Os ensaios de microscopia eletrônica de varredura (MEV), foram realizados em um equipamento JEOL JSM 6030 a $10 \mathrm{kV}$. Todas a mantas foram recobertas por uma fina camada de ouro.

Por meio da imagem de micrografia obtida pelo MEV, com o auxílio do software ImageJ, versão 1.49p, de domínio público, foram avaliados os diâmetros das fibras. Foi traçada uma linha perpendicular ao comprimento da fibra e atribuiu-se um valor para este diâmetro, com base na escala da micrografia. Para cada amostra foram mensurados 80 valores de diâmetros das fibras manualmente. Posteriormente estes dados foram processados por meio do software minitab 17 , gerando o gráfico de histograma, caracterizando a distribuição dos diâmetros das fibras com relação à frequência com que estes ocorreram na amostra.

\subsection{Calorimetria Exploratória Diferencial (DSC)}

Para efeito de comparação as melhores mantas de PHB eletrofiadas e PHB em pó foram analisadas por calorimetria exploratória diferencial (DSC), e comparadas com PHB em pó. As medidas no DSC foram realizadas um equipamento Mettler-Toledo DSC 800 . As amostras foram seladas em panelas de alumínio e aquecidas, em atmosfera inerte de nitrogênio, de -25 a $200{ }^{\circ} \mathrm{C}$ com taxa de aquecimento de $10^{\circ} \mathrm{C} \cdot \mathrm{min}^{-1}$. Não houve um segundo aquecimento no intuito avaliar o histórico térmico do PHB em pó e eletrofiado.

\subsection{Análise Termogravimétrica (TGA)}

As análises do PHB eletrofiado e fundido foram realizadas em um equipamento TA Instruments Q50 para avaliar a estabilidade térmica das misturas. As amostras foram aquecidas de 25 a $600^{\circ} \mathrm{C}$ a uma taxa de aquecimento de $10^{\circ} \mathrm{C} \cdot \mathrm{min}^{-1}$, sob atmosfera de nitrogênio.

\subsection{Difração de Raios-X (DRX)}

A análise de difração de raios-X (DRX), foi efetuada à temperatura ambiente num difratômetro Bruker D8 Advance, utilizando uma radiação de raios- $\mathrm{X}$ de $\mathrm{Cu} \mathrm{Ka}$.

\subsection{Obtenção das células para viabilidade celular}

As células-tronco mesenquimais de tecido adiposo humano (ADSCs) foram isoladas de pacientes do sexo feminino, a partir do tecido adiposo descartado de cirurgias cosméticas de lipoescultura. O procedimento foi aprovado pelo Comitê de Ética em Pesquisa da Faculdade de Ciências Médicas e da Saúde-PUC-SP, número do parecer 681.667. Após a coleta do tecido adiposo de forma asséptica, realizou-se a lavagem com PBS. A digestão do tecido foi feita com solução de tripsina/EDTA (Cultilab), seguida da centrifugação a $1500 \mathrm{rpm}$ por 10 minutos. O pellet foi ressuspendido em Dulbecco's modified Eagle's medium (DMEM) contendo $10 \%$ de soro fetal bovino. As células foram semeadas em garrafas para cultura celular e mantidas em incubadora com temperatura $\left(37^{\circ} \mathrm{C}\right)$ e atmosfera de $\mathrm{CO}_{2}$ controlada $(5 \% \mathrm{em}$ ar). Após confluência as ADSCs foram tripsinizadas e utilizadas nos experimentos na $3^{\mathrm{a}}$ passagem.

\subsection{Cultivo das células}

O ensaio de viabilidade celular foi realizado após 1 e 5 dias de incubação. Para isso as amostras de PHB foram esterilizadas por 30 min em UV e ambientadas por 24 horas em DMEM puro. As células foram semeadas a uma concentração de $1 \times 10^{4}$ células/mL de DMEM contendo $10 \%$ de soro fetal bovino. Após os períodos de incubação as células viáveis foram quantificadas pelo ensaio de MTT (3-(4,5-dimetiltiazol-2-il)-2,5- 
difenil tetrazolium brometo) (Sigma, EUA) [27]. A absorbância foi lida em leitor de microplacas Elx-800UV (Bio-Tek Instruments, EUA), com emprego de filtro com comprimento de onda de $570 \mathrm{~nm}$.

\subsection{Caracterização das células}

Devido à capacidade das células mesenquimais diferenciarem-se em adipócitos e osteoblastos, essas foram caracterizadas através de análise morfológica [28]. Para essa análise utilizou-se os corantes Oil Red que evidencia o acúmulo intracelular de lipídeos [29] indicando a diferenciação em adipócitos e o Vermelho de Alizarina que cora cálcio [30] indicando a diferenciação em osteoblasto. Para isso as células foram semeadas a uma concentração de $1 \times 10^{4}$ células/mL em DMEM contendo $10 \%$ de soro fetal bovino, após três dias de cultivo utilizaram-se respectivamente os meios de cultura para diferenciação osteogênica e adipogênica (Invitrogen). Após 14 dias de cultivo as células foram coradas com Oil Red e Vermelho de Alizarina.

\section{RESULTADOS}

\subsection{Efeito da variação da vazão da solução}

O estudo avaliando o efeito do fluxo da solução na formação das fibras, Figuras 2, 3 e 4, apontou um valor ótimo de velocidade da bomba de 3,0 mL/h, (Fig. 3), o que corresponde a uma vazão real de 5,8 mL/h. Observou-se que valores inferiores a $1,5 \mathrm{~mL} / \mathrm{h}$ ou superiores a $4,5 \mathrm{~mL} / \mathrm{h}$ inviabilizam a produção de fibras de boa qualidade. Observa-se através dos histogramas que não houve variação considerável no diâmetro das fibras nos três ensaios.

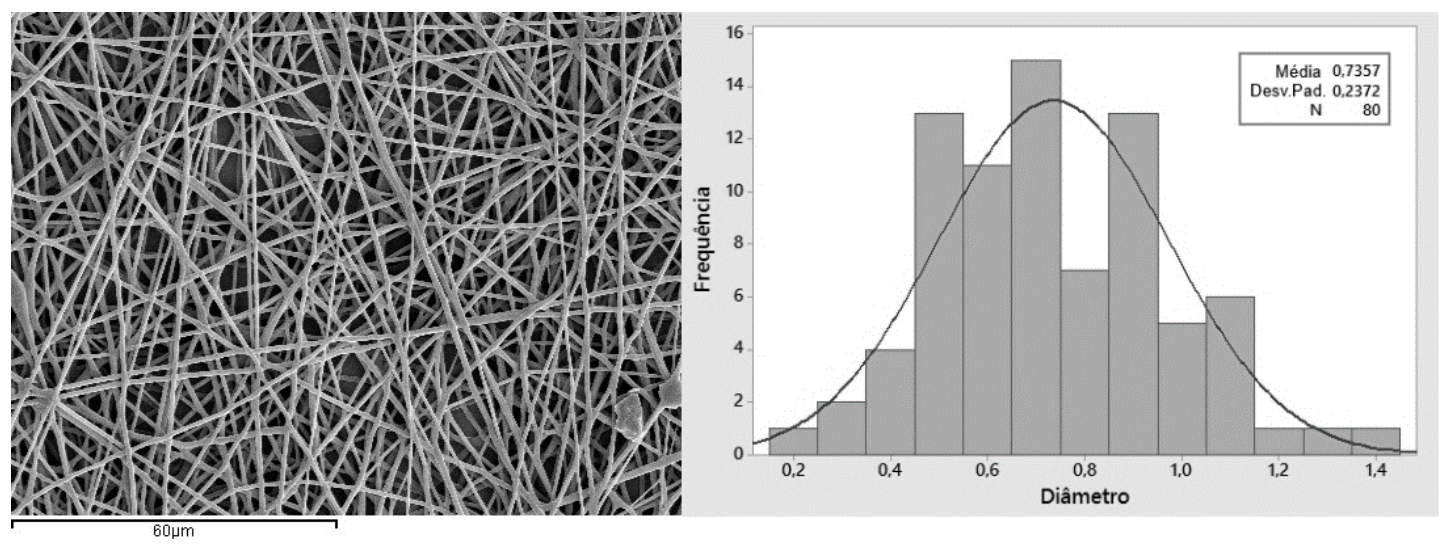

Figura 2: Micrografia das fibras eletrofiadas (magnitude 1000x) e histograma de distribuição de diâmetro de fibras do ensaio 'A', com tensão de $17 \mathrm{kV}$, vazão de $1,5 \mathrm{~mL} / \mathrm{h}$, e temperatura de $20^{\circ} \mathrm{C}$.
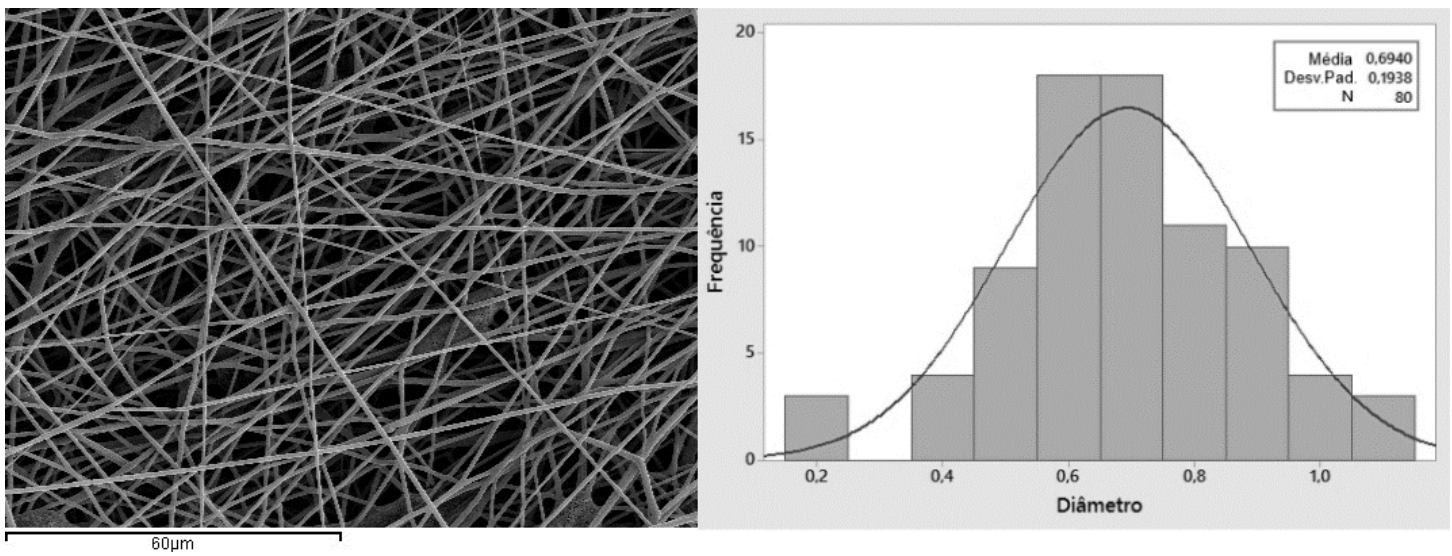

Figura 3: Micrografia das fibras eletrofiadas (magnitude 1000x) e histograma de distribuição de diâmetro de fibras do ensaio 'B', com tensão de $17 \mathrm{kV}$, vazão de $3 \mathrm{~mL} / \mathrm{h}$, e temperatura de $20^{\circ} \mathrm{C}$. 

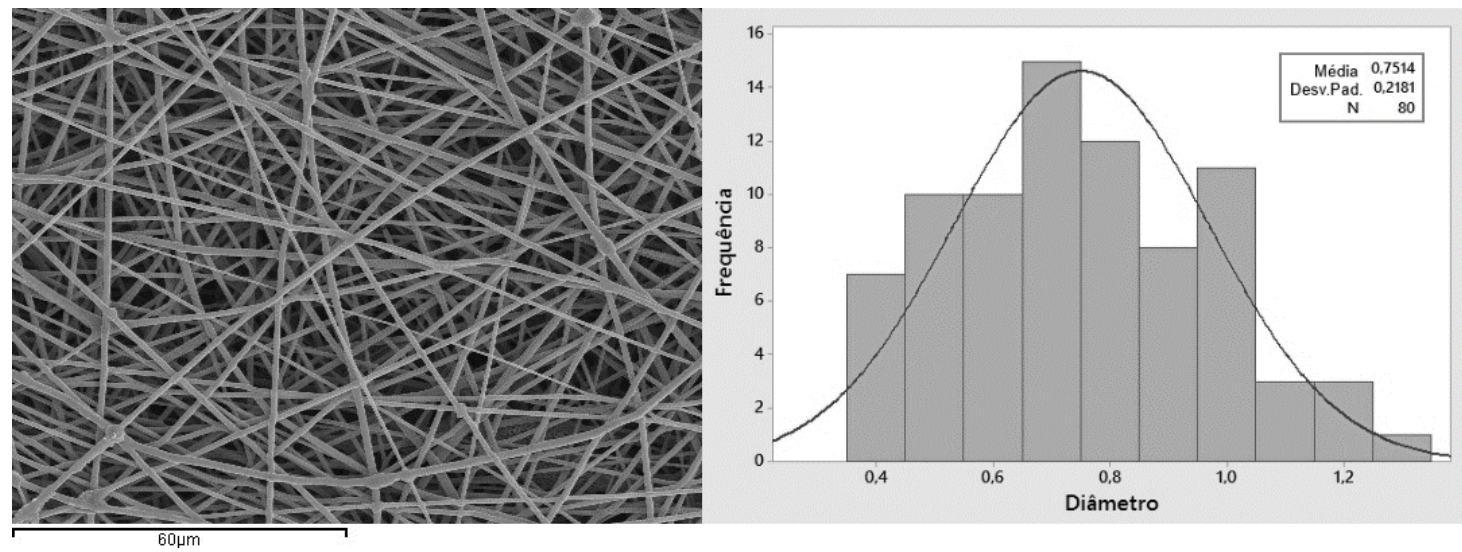

Figura 4: Micrografia das fibras eletrofiadas (magnitude 1000x) e histograma de distribuição de diâmetro de fibras do ensaio 'C', com tensão de $17 \mathrm{kV}$, vazão de $4,5 \mathrm{~mL} / \mathrm{h}$, e temperatura de $20^{\circ} \mathrm{C}$.

\subsection{Efeito da variação do potencial aplicado}

O potencial elétrico aplicado entre a agulha e o coletor também se mostrou importante para o controle da produção das fibras. A Figura 5 mostra a imagem obtida a $15 \mathrm{kV}$, na qual houve a formação de grãos. Notase que para a produção de fibras contínuas e sem grãos, nas condições estudadas, a tensão mínima deve ser de $17 \mathrm{kV}$.
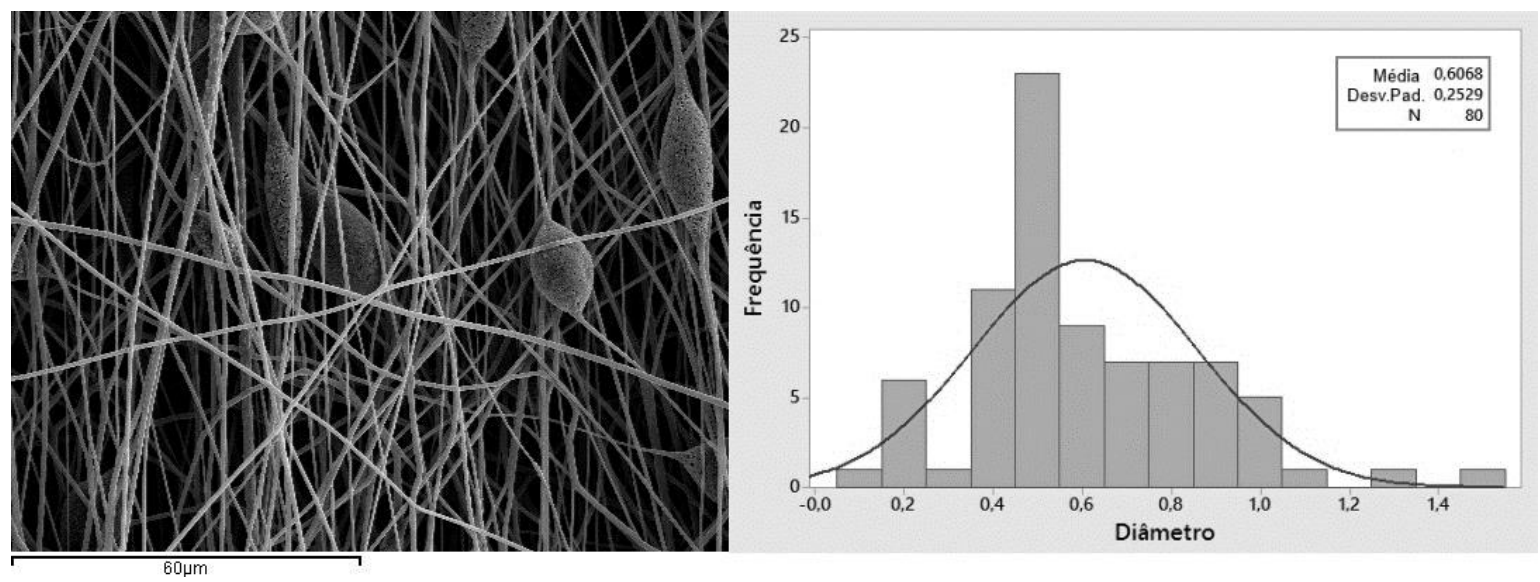

Figura 5: Micrografia das fibras eletrofiadas (magnitude 1000x) e histograma de distribuição de diâmetro de fibras do ensaio ' $\mathrm{D}$ ', com tensão de $15 \mathrm{kV}$, vazão de $3 \mathrm{~mL} / \mathrm{h}$ e temperatura de $20^{\circ} \mathrm{C}$.

\subsection{Efeito da adição do surfactante SDS}

Um melhoramento do processo foi alcançado pela adição de $0,5 \% \mathrm{~m} / \mathrm{m}$ de um surfactante (SDS) à solução de PHB em CF/DMF (9/1). Neste caso, conforme mostrado na Figura 6, observa-se a formação de uma rede mais densa de fibras de PHB e com poros interconectados, propiciando a obtenção de mantas com melhor desempenho mecânico. Não houve variação significativa no diâmetro das fibras também. 

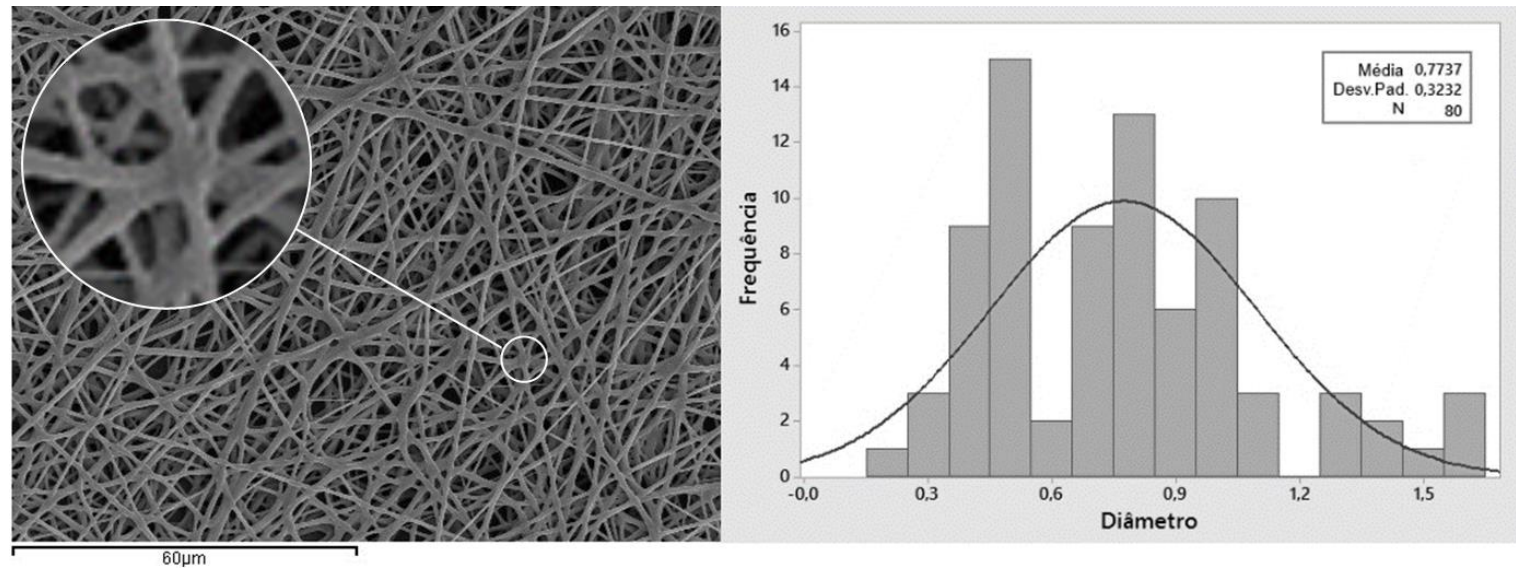

Figura 6: Micrografia das fibras eletrofiadas (magnitude 1000x) e histograma de distribuição de diâmetro de fibras do ensaio 'E', com tensão de $15 \mathrm{kV}$, vazão de $3 \mathrm{~mL} / \mathrm{h}$ e temperatura de $20^{\circ} \mathrm{C}$.

\subsection{Efeito da variação da temperatura da solução}

Em relação à temperatura da solução, mostra-se Figura 7, que o processo pode ser ainda melhorado pelo aumento da temperatura até $50{ }^{\circ} \mathrm{C}$, condição em que se obtém mantas mais densas e com fibras de menores diâmetros, média de $0,52 \mu \mathrm{m}$.
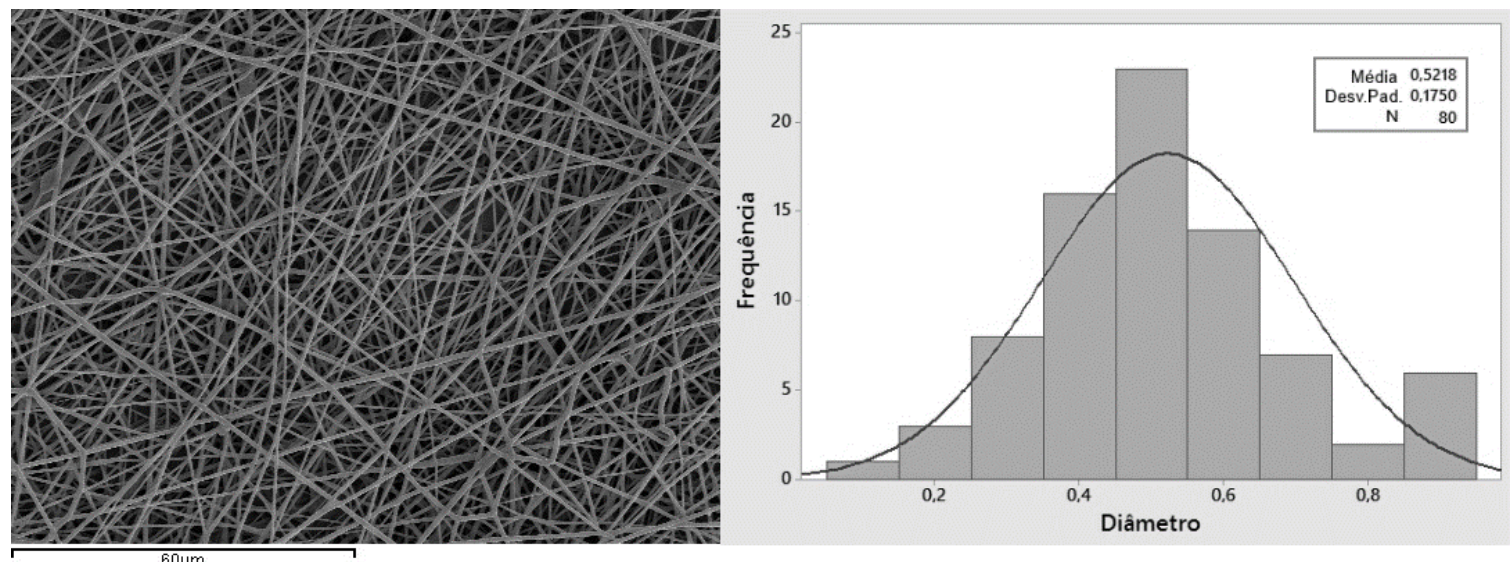

Figura 7: Micrografia das fibras eletrofiadas (magnitude 1000x) e histograma de distribuição de diâmetro de fibras do ensaio 'F', com tensão de $17 \mathrm{kV}$, vazão de $3 \mathrm{~mL} / \mathrm{h}$, e temperatura de $50^{\circ} \mathrm{C}$.

\subsection{Estudo do comportamento térmico das mantas eletrofiadas de PHB}

Os resultados das análises termogravimétricas (TG), Figura 8 mostram que a degradação acontece em um único estágio e que o material degrada totalmente em aproximadamente $250{ }^{\circ} \mathrm{C}$. É importante ressaltar que a temperatura de início de degradação é consideravelmente maior que a observada para o PHB em pó ou processado por injeção que de acordo com a literatura é de aproximadamente $170^{\circ} \mathrm{C}[21,17]$. 


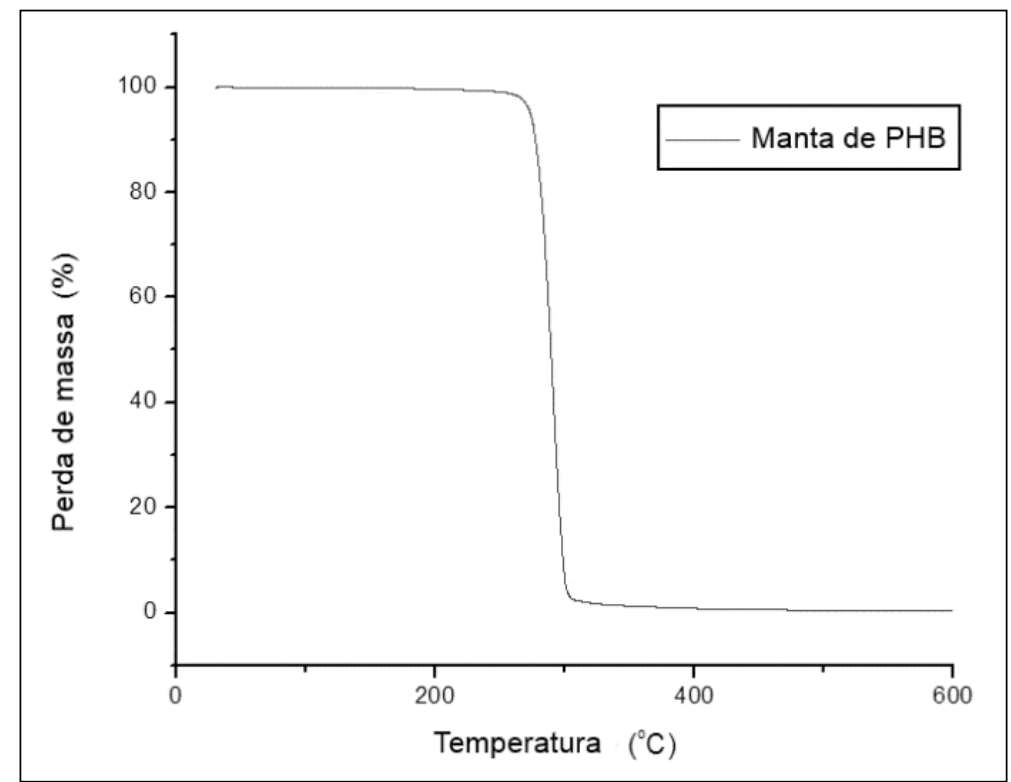

Figura 8: Curvas de TG para fibras PHB obtidas por eletrofiação.

As curvas calorimétricas, Figura 9, demonstram que as fibras de PHB obtidas por eletrofiação são bastante cristalinas, sendo que a presença de apenas uma Tm (temperatura de fusão), a aproximadamente $175^{\circ} \mathrm{C}$, sugere a existência de apenas uma forma cristalina. Este perfil difere do observado para o PHB em pó, que apresenta três picos de fusão, entre 160 e $180^{\circ} \mathrm{C}$, provavelmente relacionados a diferentes formas cristalinas. Tal comportamento pode ser explicado pela orientação das cadeias poliméricas que ocorre durante o processo de eletrofiação.

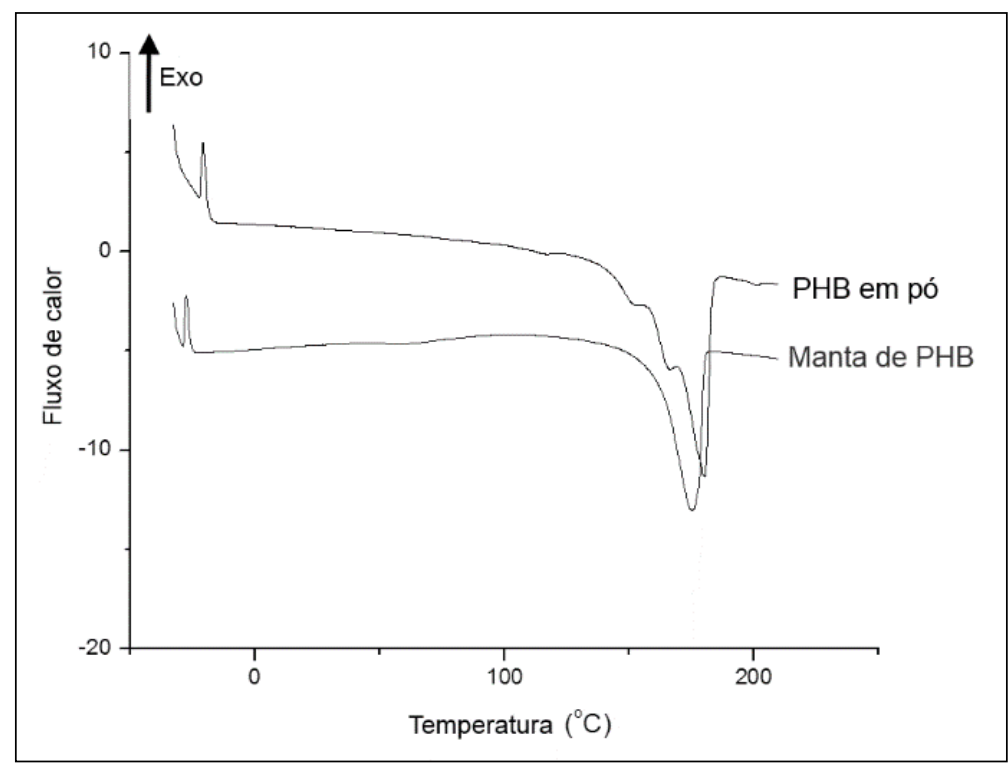

Figura 9: Curvas de DSC para o PHB em pó e eletrofiado.

\subsection{Difração de Raio-X (DRX)}

Os difratogramas apresentam picos de cristalinidade claramente definidos tanto para o material processado por eletrofiação quanto por evaporação lenta do solvente ('casting'). Este fato demonstra uma alta cristalinidade das fibras eletrofiadas e confirma os dados observados no DSC, o qual apresentou um aumento na cristalinidade do material após a eletrofiação do mesmo. O perfil de difração de raios-X para o PHB (amostra E),

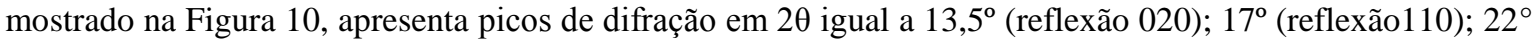
(101); 25,5 (reflexão 121), sendo similar ao padrão mostrado por [24]. 


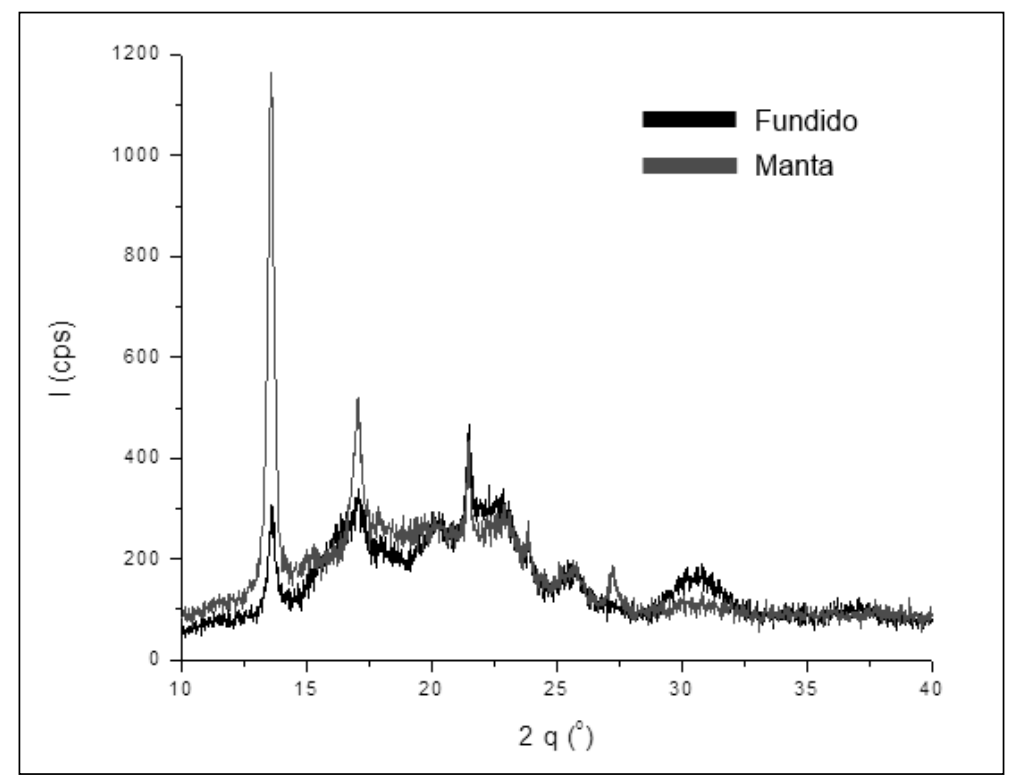

Figura 10: Difratograma da amostra 'E'.

\subsection{Cultivo das células para viabilidade Celular}

Para que um biomaterial sirva como carreador celular é necessário que esse permita a adesão e o crescimento celular. A manta correspondente ao ensaio 'E' foi selecionada e então foi destinada ao ensaio de viabilidade celular. Como resultado, observa-se na Figura 11 que ambos os tempos de 1 e 5 dias permitiram a proliferação das ADSCs, havendo crescimento celular significativo $(\mathrm{p}<0,01)$, tanto no grupo controle quanto na membrana. No tempo de $1 \mathrm{dia}$, o crescimento celular foi menor, quando comparado ao crescimento na placa de controle. Já no tempo de 5 dias, houve maior crescimento na manta de PHB, quando comparado com a placa de controle. Desta forma, obteve-se um resultado positivo quanto ao objetivo de aplicação desta técnica, de modo a permitir a proliferação celular no arcabouço polimérico.

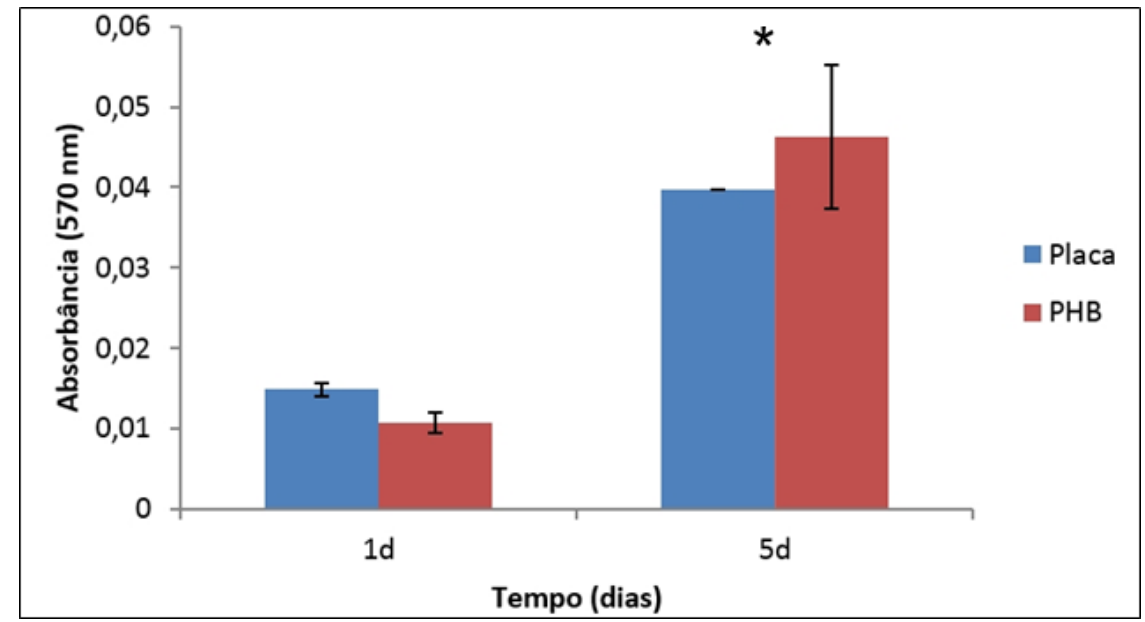

Figura 11: Ensaio de MTT após 1 e 5 dias de cultura celular nas membranas de PHB, a placa de poliestireno foi utilizada como controle. Os valores são expressos em média $\pm \mathrm{SD}, \mathrm{n}=4$. *p $<0.01$.

\subsection{Caracterização das células}

As células isoladas do tecido adiposo foram comprovadas como sendo ADSCs por meio de seu potencial de diferenciação em células do tecido mesodérmico como adipócitos e osteoblastos. Em A e B, na Figura 12, as células não foram mantidas em meio de diferenciação, mas foram coradas respectivamente com Oil Red e Vermelho de Alizarina para serem utilizadas como controle da coloração. Em C e D as células foram mantidas nos meios de diferenciação. 

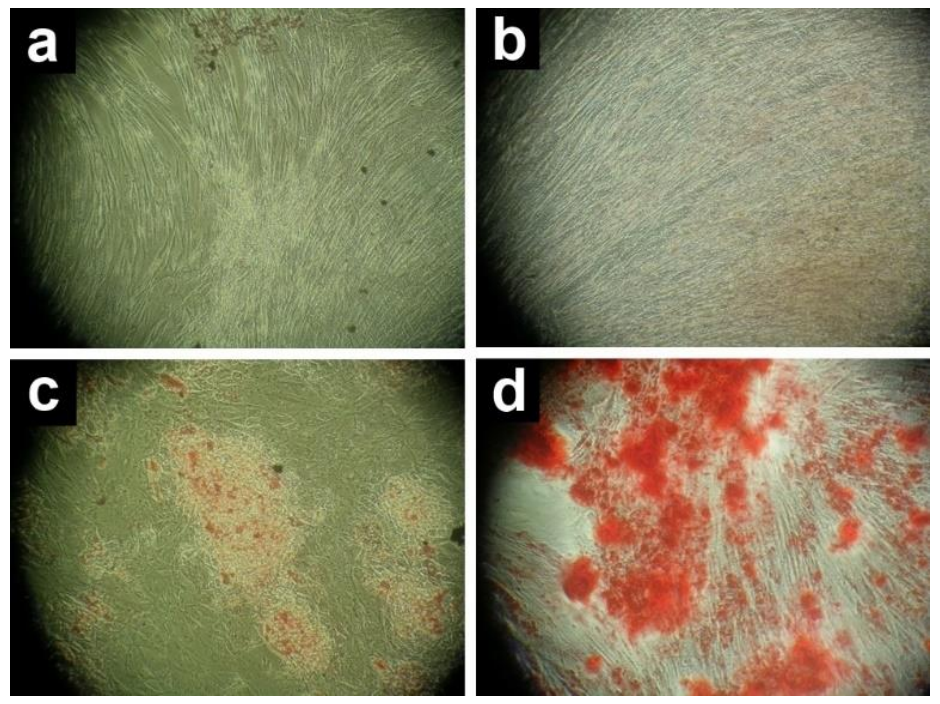

Figura 12: Caracterização das ADSCs após indução com meio de cultivo adipogênico (C) e osteogênico (D). Diferenciação em adipócitos e coloração com Oil red (A e C). Diferenciação em osteoblastos e coloração com Vermelho de Alizarina (B e D).

\section{CONCLUSÕES}

A partir dos resultados obtidos pode-se concluir primeiramente que é possível se obter fibras do biopolímero PHB por eletrofiação. As mantas obtidas são potencialmente interessantes para curativos, por sua biocompatibilidade e bioreabsorção pelo corpo humano.

Dentre os resultados dos ensaios, analisando-se as micrografias obtidas por MEV, observa-se que o aumento do fluxo da solução e da tensão não influenciaram no diâmetro médio das fibras. Porém com o aumento do potencial elétrico há a diminuição da formação de grãos, a mesma tendência também foi observada para o aumento da vazão da solução, até um certo valor máximo de fluxo (cerca de 4,5 mL/h), acima do qual é observado novamente a formação dos grãos. Diferentemente, o aumento da temperatura proporciona uma diminuição do diâmetro médio das fibras.

A análise térmica por TG evidenciou maior estabilidade térmica para o PHB eletrofiado quando comparado ao PHB em pó, este fato deve-se a diferentes formas cristalinas que podem ser também observadas no DSC. Os difratogramas demonstram uma alta cristalinidade das fibras eletrofiadas e confirmam os dados observados por DSC.

Este estudo mostrou quais os melhores parâmetros para se obter uma morfologia mais adequada à aplicação em engenharia de tecidos, apresentando as fibras mais finas, com um diâmetro médio uniforme e não apresentando formação de grãos e com poros interconectados, sendo estes: a concentração da solução de $10 \%$ (m/v) em CF/DMF (9/1), fluxo da solução de 3,0 ml/h (indicação na bomba) e fluxo real de 5,8 mL/h, tensão de $17 \mathrm{kV}$ e adição de surfactante (dodecil-sulfato de sódio, SDS).

Após o ensaio de viabilidade celular com células tronco-mesenquimais na melhor manta, observou-se que as amostras de PHB permitiram a adesão e crescimento celular ao longo do tempo, indicando que as mantas não foram citotóxicas. $\mathrm{O}$ que possibilita o uso desse material como arcabouços para crescimento celular.

Estima-se que as melhores propriedades da amostra escolhida como: uniformidade das fibras, a não formação de grãos, poros interconectados bem como uma visível tridimensionalidade da manta, permitiram a proliferação das células quando cultivadas, possibilitando este resultado positivo. De fato, para a aplicação em engenharia de tecidos, é necessária uma matriz tridimensional, mecanicamente estável e com poros interconectados, para que as células possam crescer por toda a estrutura [25, 26].

No que diz respeito ao alinhamento das fibras, mesmo tendo sido utilizado um coletor rotativo, que naturalmente tende a alongar as fibras em um único sentido, observou-se que nenhum ensaio apresentou alinhamento significativo. No entanto, considerando o tipo de tecido cultivado, a aleatoriedade das fibras não apresentou barreira a proliferação das respectivas células. 


\section{BIBLIOGRAFIA}

[1] DOSHI, J., RENEKER, D. H., "Electrospinning Process and Applications of Electrospun Fibers", Journal of Electrostatics, v. 35, pp. 151-160, 1995.

[2] XIN, Y., RENEKER, D. H., "Garland formation process in electrospinning”, Polymer, v.53, pp. 3629$3635,2012$.

[3] HUANG, Z.M., ZHANG, Y.Z., KOTAKI, M., et al., "A review on polymer nanofibers by electrospinning and their applications in nanocomposites", Composites Science and Technology, v. 63, pp. 2223-2253, 2003.

[4] TAYLOR, G.I., "Electrically Driven Jets”, Proc R Soc Lond, v.313, pp. 453-475, 1969.

[5] RENEKER, D.H., YARIN, A.L., ZUSSMAN, E., XU, H., "Electrospinning of Nanofibers from Polymer Solutions and Melts", Advances in applied mechanics, v. 41, pp.43-197, 2007.

[6] VRIEZE, S., CLERCK, K., 80 years of electrospinning. Department of Textile, p. 60, 2009.

[7] TIJING, L. D., CHOIA, W., JIANG, Z., et al., "Two-nozzle electrospinning of (MWNT/PU)/PU nanofibrous composite mat with improved mechanical and thermal properties", Current Applied Physics, pp. 1-9, 2013.

[8] ÁVILA JÚNIOR, J., ÁVILA, A. F., TRIPLETT, M. H., "Caracterização Morfológica de Nanomembranas de Poliamida-66 Dopadas com Grafeno Obtidas por Electrospinning", Polímeros, v. 23, n. 1, pp. 74-81, 2013.

[9] BHARDWAJ, N., KUNDU, S. C., "Electrospinning: A fascinating fiber fabrication technique", Biotechnology Advances, pp. 325-347, 2010.

[10] TONCHEVA, A., PANEVA, D., MANOLOVA, N., et al., "Dual vs. Single Spinneret Electrospinning for the Preparation of Dual Drug Containing Non-Woven Fibrous Materials", Colloids and Surfaces A, pp. 123, 2012.

[11] FURTH, M. E., ATALA, A., VAN DYKE, M. E., "Smart biomaterials design for tissue engineering and regenerative medicine", Biomaterials, v. 28, 5068-5073, 2007.

[12] UITTO, J., OLSEN, D. R., FAZIO, M. J., "Extracellular Matrix of the Skin: 50 Years of Progress", The journal of investigative dermatology, v. 92, n. 4, pp. 61-77, 1989.

[13] REMPEL, L. C. T., TIZZOT, M. R. P. A., VASCO, J. F. M., "Incidência de infecções bacterianas em pacientes queimados sob tratamento em hospital universitário de Curitiba", Revista Bras. de Queimaduras, v. 10 , n.1, pp. 3-9, 2011.

[14] PORTELA, P. M. D., Montagem e automatização de um sistema de Electrospinning, Dissertação de M.Sc., Universidade do Minho, Portugal, 2010.

[15] JENTZSCH, E., GÜL, Ö., ÖZNERGIZ, E., “A comprehensive electricfield analysis of a multifunctional electrospinning platform”, Journal of Electrostatics, v.71, n.3, pp.294-298, 2013.

[16] COSTA, R. G. F., OLIVEIRA, J. E., PAULA, G. F., et al., "Eletrofiação de Polímeros em Solução. Parte I: Fundamentação Teórica", Polímeros, v. 22, n. 2, pp. 170-177, 2012.

[17] DUARTE, M. A. T., Influência das concentrações do PCL-T em membranas de PLDLA. Estudo in vitro e in vivo, Tese de D.Sc., Universidade estadual de campinas, Campinas, Brasil, 2009.

[18] SILL, T. J., RECUM, H. A., "Electrospinning: Applications in drug delivery and tissue engineering", Biomaterials, v. 29, pp. 1989-2006, 2008.

[19] TIAN, H., TANG, Z., ZHUANG, X., et al., "Biodegradable synthetic polymers: Preparation, functionalization and biomedical application", Progress in Polymer Science, v. 37, 237-280, 2012.

[20] COUTINHO, B. C., MIRANDA, G. B., SAMPAIO, G. R., et al., "A importância e as vantagens do polihidroxibutirato (plástico biodegradável)", Holos, Ano 20, pp. 76-81, 2004.

[21] GHAFFAR, A. M. E. A., Development of a biodegradable material based on poly (3-hidroxibutyrate) PHB. Tese de D.Sc., Universidade Martin-Luther, Halle-Wittenberg, Alemanha, 2002.

[22] CHEN, Q., LIANG, S., THOUAS, G. A., "Elastomeric biomaterials for tissue engineering", Progress in Polymer Science, v. 38, pp. 584-671, 2013.

[23] PELLICANO, M., PACHEKOSKI, W., AGNELLI, J. A. M., "Influência da Adição de Amido de Mandioca na Biodegradação da Blenda Polimérica PHBV/Ecoflex", Polímeros: Ciência e Tecnologia, v. 19, n. 3, pp. 212-217, 2009. 
[24] IKEJIMA, T., INOUE, Y., "Crystallization behavior and environmental biodegradability of the blend films of poly (3-hydroxybutyric acid) with chitin and chitosan”, Carbohydrate, Polymers, v.41, pp.351-356, 2000.

[25] PARK, J. B. Biomaterials an Introduction, Plenum Press, New York, 1979.

[26] HENCH, L. L., ETHRIDGE, E. C. Biomaterials an Interfacial Approach, Academic Press, New York, 1982.

[27] BERRIDGE, MV, TAN, AS. "Characterization of the cellular reduction of 3-(4,5dimethylthiazol-2-yl)-2,5-diphenyltetrazolium bromide (MTT): subcellular localization, substrate dependence, and involvement of mitochondrial electron transport in MTT reduction", Arch Biochem Biophys", v.303, n.2, pp. 474-82, 1993.

[28] DOMINICI, M, LE BLANC, K, MUELLER, I, et al., "Minimal criteria for defining multipotent mesenchymal stromal cells. The International Society for Cellular Therapy position statement", Cytotherapy, v.8, pp.315-317, 2006.

[29] PREECE A: A manual for histologic technicians. Boston. MA. Little, Borwn and Co, 1972.

[30] LIU, TM, MARTINA, M, HUTMACHER, DW, et al., "Identification of comm-pathways mediating differentiation of bone marrow- and adipose tissue-derived human mesenchymal stem cells into three mesenchymal lineages", Stem Cells, v.25, pp.750-60, 2007. 